\title{
ESTUDO DE CASO: ANÁLISE FINANCEIRA DOS RESULTADOS DA SILVAN TRANSPORTES-ME
}

\section{ARTIGO ORIGINAL}

CARVALHO, Melissa da Silva ${ }^{1}$

SANTOS, Nilson Souza dos ${ }^{2}$

BREVES, Ricardo de Almeida ${ }^{3}$

OLIVEIRA, Elisângela Leitão de ${ }^{4}$

CARVALHO, Melissa da Silva. Et al. Estudo de Caso: Análise Financeira dos Resultados da Silvan Transportes-ME. Revista Científica Multidisciplinar Núcleo do Conhecimento. Ano 05, Ed. 01, Vol. 08, pp. 144-161. Janeiro de 2020. ISSN: 24480959, Link de acesso: https://www.nucleodoconhecimento.com.br/administracao/analise-financeira

\section{RESUMO}

O sucesso de uma organização seja ela de pequeno, médio ou grande porte depende não apenas de recursos humanos e físicos, mas também dos recursos financeiros, que irão indicar a saúde da empresa. O estudo procurou identificar o controle financeiro da Silvan Transportes-ME, demonstrar a importância do fluxo de caixa para empresas de pequeno porte, desenvolver esse demonstrativo e, ao fim, realizar uma análise da situação financeira da entidade. Para alcançar tais objetivos, foi realizada entrevista com o proprietário da empresa, além de observações documentais.

\footnotetext{
${ }^{1}$ Graduação em Administração.

2 Doutorado em Biotecnologia, Mestre em Engenharia de Produção, Pós-Graduação em Engenharia de Produção, Graduação em Administração.

${ }^{3}$ Mestre em Engenharia de Produção e Ciência Econômica.

${ }^{4}$ Mestre em Engenharia de Produção, Graduação em Ciências Contábeis.
} 
Constatou-se que o controle financeiro da empresa estava desatualizado, indicando saldo positivo, quando, na verdade o saldo era negativo. Assim, o chefe do empreendimento considerou adotar o método do fluxo de caixa para tomar melhores decisões.

Palavras-chave: Fluxo de caixa, análise financeira, empresa de pequeno porte.

\section{INTRODUÇÃO}

O cerne de uma empresa baseia-se não só na sua estrutura física ou composição de seu pessoal. Ambos são de suma importância para o bom funcionamento da organização, porém sem a gestão financeira orçamentária, com suas constantes análises do caixa e patrimônio, bem como projeções futuras, a expansão e consolidação da empresa pode estar comprometida.

A área de finanças engloba atividades que pertencem aos administradores. Eles utilizam dados levantados pela contabilidade e pela matemática financeira aplicada para a tomada de decisões. A contabilidade utiliza diversas ferramentas para analisar as constantes variações do patrimônio, sendo uma delas, a escrituração nos livros próprios, que auxiliam no planejamento de crescimento, verificação de desperdícios e, como falado, ajudam na melhor tomada de decisão.

Empresas de pequeno porte não possuem a obrigação de terem suas finanças escrituradas, no entanto, sempre é bom ter domínio das entradas e saídas do caixa, para não perder oportunidades ou mesmo tomar decisões sem o conhecimento do capital próprio.

O presente artigo teve como objeto de estudo a Silvan Transportes-ME, uma microempresa de transporte escolar da cidade de Manaus. Seu início se deu no ano de 2004 contando com um carro de doze lugares e dois funcionários. Atualmente, a empresa possui dois carros cadastrados, sendo uma van de dezesseis lugares e um micro-ônibus de vinte e quatro lugares e três funcionários. 
Em observações preliminares, não foi constatada uma gestão financeira nesta empresa, verificando apenas uma planilha de recebimentos de alimentada apenas no início do ano, período de entrada de alunos, ajuste de rotas e datas de pagamento.

Assim, este instrumento teve como objetivos a identificação do controle financeiro da empresa, o levantamento da situação financeira atual através dos índices de Liquidez Corrente, Solvência Geral, Participação de Terceiros, Participação do Capital Próprio sobre o Ativo, Participação do Capital Próprio sobre o Capital de Giro, Composição do Endividamento e Situação Líquida Patrimonial, o apontamento da importância do controle financeiro através de pesquisas bibliográficas e a proposta do controle de caixa, através do fluxo de caixa, que contribui com o planejamento dos custos e observação dos pagamentos e recebimentos.

\section{FUNDAMENTAÇÃO TEÓRICA}

\subsection{ADMINISTRAÇÃO FINANCEIRA}

O termo finanças pode ser definido como "a arte e a ciência de administrar o dinheiro". (GITMAN, 2010, p. 3;)

Para Groppelli \& Nikbakht (2010, p.3), "finanças são a aplicação de uma série de princípios econômicos e financeiros para maximizar a riqueza ou o valor total de um negócio".

Para que as decisões sejam tomadas, sejam obtidas as previsões de custos e lucros, todos os funcionários de todas as áreas devem estar em constante compartilhamento de informações com os funcionários de finanças.

Segundo Gitman (2010, p. 4), "os administradores financeiros são responsáveis pela gestão dos negócios financeiros de organizações de todos os tipos - financeiras ou não, abertas ou fechadas, grandes ou pequenas, com ou sem fins lucrativos". 
Além das informações obtidas com a interação de todos os funcionários de todas as áreas da empresa, os administradores financeiros baseiam-se nos relatórios dos demonstrativos financeiros para a tomada de decisão.

Conforme Groppelli \& Nikbakht (2010, p.13):

Os demonstrativos financeiros auxiliam os administradores a tomar decisões envolvendo o melhor uso do caixa, a realização de operações eficientes, a melhor alocação de fundos entre os ativos e o financiamento eficaz de operações e de investimentos. Para interpretar os demonstrativos financeiros usam-se, em parte, índices financeiros, relatórios gerenciais, demonstrativos de origens e aplicações de recursos e orçamentos de caixa.

"A administração financeira é o ofício do planejamento, da organização e da preservação de riscos ou de situações indesejáveis no futuro". (ANTONIK, 2016, p. 13)

\subsection{DEMONSTRATIVO DO FLUXO DE CAIXA}

O Fluxo de Caixa é uma demonstração de fácil utilização, não sendo necessário equipamentos específicos para obter controle das finanças.

Para Ribeiro (2013, p. 367), "a Demonstração dos Fluxos de Caixa (DFC) é um relatório contábil que tem a finalidade de evidenciar as transações ocorridas em um determinado período e que provocam modificações no saldo do caixa da empresa".

Para Camargo (2007, p. 68):

A Demonstração do Fluxo de Caixa - DFC evidencia todas as transações empresariais que afetam o caixa da empresa, analisando a origem dos recursos disponíveis, onde estes foram aplicados e qual o resultado do fluxo financeiro da empresa. 
Segundo Assaf Neto (2017, p. 33):

O fluxo de caixa é um instrumento que relaciona os ingressos e saídas (desembolsos) de recursos monetários no âmbito da empresa em determinado intervalo de tempo. A partir da elaboração do fluxo de caixa é possível prognosticar eventuais excedentes ou escassez de caixa, determinando-se medidas saneadoras a serem tomadas.

Os três autores acima citados, convergem para o entendimento que o Fluxo de Caixa permite a visibilidade de todas as entradas e saídas em determinado período, sendo possível perceber a alocação dos recursos.

Ching, Marques e Prado (2007, p. 69) indicam que a Demonstração do Fluxo de Caixa são usadas para:

Analisar a liquidez e a flexibilidade financeira. Liquidez refere-se à disponibilidade de recursos para pagar obrigações. Flexibilidade financeira refere-se à habilidade de a empresa financiar suas operações com recursos gerados internamente ou com recursos externos, por meio de emissão de ações, debêntures ou empréstimos. Os analistas de crédito e os investidores estão particularmente interessados nessas avaliações.

Avaliar as decisões gerenciais. Decisões inteligentes levam a empresa a produzir lucro e gerar fluxos de caixa. Más decisões podem levá-la à falência. Ao observar na Demonstração os investimentos que a empresa realizou no passado, pode-se concluir se esses investimentos estão trazendo retorno sob forma de lucro e fluxo de caixa.

Determinar a capacidade de pagar dividendos aos acionistas e empréstimo aos credores. Os acionistas estão interessados em receber dividendos de seus investimentos, bem como os credores, no tocante ao principal e aos juros. A Demostração mostrará se a empresa está 
pagando dividendos e empréstimo com caixa gerado internamente ou com novo endividamento.

Mostrar a relação entre o lucro líquido e o caixa. Normalmente, caixa e lucro andam juntos. Altos lucros levam a aumentos no caixa, e viceversa.

Ajustar a prever futuros fluxos de caixa. Fontes e saídas de caixa de períodos anteriores são bons indicativos de geração de caixa futuro. Os analistas financeiros usam o valor presente dos fluxos de caixa previstos para avaliar o valor da empresa.

Os fluxos de caixa podem ser divididos em fluxos operacionais, fluxos de investimentos e fluxos de financiamento, os quais Gitman (2010, p. 98) define:

Os fluxos de caixa operacionais constituem as entradas e saídas de caixa diretamente relacionadas à venda e produção de bens e serviços. Os fluxos de investimentos representam os fluxos de caixa associados à venda de ativo imobilizado e investimentos em participações societárias. [...] Os fluxos de financiamento provêm de transações financeiras com capital de terceiros (dívidas) ou capital próprio.

Alguns autores como Groppelli \& Nikbakht (2010) e Ribeiro (2013) entendem essa divisão dos fluxos de caixa como sendo atividades, quais sejam atividades operacionais, atividades de financiamento e atividades de investimento. No entanto, os conceitos são idênticos aos propostos por Gitman (2010).

O Fluxo de Caixa pode ser elaborado por dois métodos: direto e indireto. Camargo (2007, p. 70) os define como:

O fluxo de caixa direto facilita a visualização e a compreensão do fluxo financeiro, pois demonstra de forma detalhada os recebimentos e os pagamentos provenientes das atividades empresariais. 


\section{$[\ldots]$}

O fluxo de caixa indireto é construído a partir das demonstrações financeiras e evidencia as razões para a mudança de saldo da conta caixa de um período para outro, em função da alteração das demais contas do ativo e do passivo.

Pelo exposto, a demonstração do fluxo de caixa se mostra importante devido o esclarecimento das entradas e saídas do caixa, contas a pagar e a receber, e, ao final identifica lucros ou despesas da organização, auxiliando os administradores financeiros na progressão aos objetivos traçados ou identificação dos pontos ineficientes.

\subsection{IMPORTÂNCIA DO CONTROLE FINANCEIRO PARA MICRO E PEQUENAS EMPRESAS}

As pequenas empresas estão dispensadas das escrituras contábeis, conforme estabelece o art. 1.179, § $2^{\circ}$ da Lei $n^{\circ}$ 10.406/2002. No entanto, é importante que as empresas possuam formas de acompanhar suas finanças para a melhor tomada de decisão.

"Nas micro e pequenas empresas o cérebro e o gestor são apenas uma pessoa: o proprietário". (ANTONIK, 2016, p. 4)

Ao ser o cérebro e o gestor, o proprietário de uma micro e pequena empresa "será o responsável pelo planejamento, controle, imposição dos limites dos gastos, mas também irá avaliar custos, projetos e oportunidades" (ANTONIK, 2016, p. 13), necessitando, portanto, de um suporte para atingir os objetivos citados.

Segundo Sousa (2014, p. 2), "as micro e pequenas empresas, tal como empresas de qualquer porte, dependem do controle financeiro para manterem sua "saúde" e obter lucratividade." 
Ainda conforme Sousa (2014, p. 3)," a empresa até poderá obter lucros sem usar métodos técnicos, mas certamente será maior se ela for bem administrada."

Em suma, há convergência quanto ao entendimento de que as micro e pequenas empresas necessitam ter o controle financeiro para aumentar sua capacidade de lucro, cabendo ao gestor (proprietário) esse compromisso, tendo em vista que ele é o responsável pelo planejamento, controle, organização e direção da empresa.

\section{METODOLOGIA}

Segundo Vergara (2013), a pesquisa pode ser definida quanto aos fins e aos meios. Os fins da pesquisa podem ser exploratórios, descritivo, explicativo, metodológico, aplicado e intervencionista. E, os meios de investigação podem ser pesquisa de campo, pesquisa de laboratório, documental, bibliográfica, experimental, ex post facto, participante, pesquisa-ação e estudo de caso.

Esta pesquisa teve fim descritivo, uma vez que expôs as características de uma determinada população, não tendo compromisso de explicar os fenômenos ocorridos, apenas estabelecer correlações entre as variáveis e definição de sua natureza.

Quanto ao meio de investigação, este estudo ocorreu na forma de estudo de caso na Silvan Transportes-ME, que para Vergara é "circunscrito a uma ou poucas unidades, entendidas essas como pessoa, família, produto, empresa, órgão público, comunidade ou mesmo país. Tem caráter de profundidade e detalhamento" (2013, p. 44).

Um dos objetivos da pesquisa é a demonstração da importância do controle financeiro para micro e pequenas empresas, para isso utilizou-se da apresentação bibliográfica dos autores Sousa (2014) e Antonick (2016).

A coleta de dados foi feita através pesquisa documental nos arquivos da empresa referente ao exercício de 2019, atendo-se ao mês de outubro para realização do fluxo de caixa e entrevista com o administrador, composta de sete questões abertas, com $o$ intuito de verificar a forma de organização das finanças. 
Após a entrevista, foram retiradas fotografias do controle financeiro que a empresa possuía. Com os comprovantes de pagamentos e recebimentos, foi construída tabela que auxiliou a construção do fluxo de caixa da empresa referente ao mês de outubro/2019 e, a partir dos resultados, foi elaborado Balanço Patrimonial, permitindo fazer análise da situação financeira da empresa através dos índices de Liquidez Corrente, de Solvência Geral, de Participação de Terceiros, de Participação de Capital Próprio sobre o Ativo, de Participação do Capital Próprio sobre o Capital de Giro, de Composição do Endividamento, e Situação Líquida Patrimonial (SLP).

\section{ANÁLISE E DISCUSSÃO DOS RESULTADOS}

O objeto de estudo foi a empresa de transporte escolar, Silvan Transportes ME, que possui uma estrutura familiar, tem dois carros registrados junto aos órgãos competentes e três funcionários.

Os dados foram coletados através de entrevista com o proprietário da organização e pesquisa documental. $O$ intuito da entrevista foi o de tomar conhecimento mais aprofundado da forma de gestão financeira da empresa.

Primeiramente foi questionada a importância de a empresa possuir controle financeiro. Como resposta, o gestor afirmou reconhecer sua a importância para não perder o controle das despesas. Ainda, alegou que o início do ano sempre é o mais difícil tendo em vista o período de pagamento de impostos e manutenção necessária para início dos trabalhos. A empresa presta serviço privado, dependendo deles para honrar com os compromissos. Quando a organização não consegue o número suficiente de clientes, o controle financeiro é bastante utilizado para que despesas desnecessárias não sejam assumidas.

Questionado se a empresa já perdeu alguma oportunidade por conta do controle financeiro, o empresário informou que sim. Toda a renda é proveniente dos contratos particulares e não há nenhuma reserva para situações emergenciais ou investimentos. Certo ano, a empresa passou por um processo de seleção e devido a ausência de um controle financeiro que indicasse o caixa da empresa, projeção futura e ainda devido 
a falta de capital para comprar veículo que atendesse empresas do Distrito, findou perdendo o contrato.

Foi abordada a perspectiva do proprietário quanto os seus recebimentos e pagamentos, questionando se gasta mais do que ganha. $\mathrm{O}$ empresário relatou que a situação da empresa foge do controle quando acontecem imprevistos, como má qualidade do combustível que compromete bomba injetora do veículo, pane no computador central e funcionários que não correspondem com a qualidade do serviço, pois acabam permitindo gastos maiores do que os estipulados.

A pergunta seguinte referiu-se a perspectiva do gestor frente ao controle financeiro que possui, se é suficiente/vantajoso. O empresário relatou que o seu controle financeiro se resume a uma tabela do Excel que dispõe a quantidade de alunos, datas de pagamentos e valores das mensalidades. Tal ferramenta não está sendo vantajosa pois é uma tabela estática e não indica onde estão acontecendo os erros.

A autora questionou a forma das decisões quanto ao crescimento, estabelecimento de metas são tomadas pelo administrador. Como resposta, foi relatado que tudo depende da quantidade de alunos. No momento, a empresa está sem perspectiva de crescimento e investimento devido os bens ainda não estarem quitados e ainda devido ausência de reserva para investimentos.

Questionado se a empresa tem listadas todas as suas despesas e se possui todos os comprovantes de pagamentos e recebimentos, a reposta foi positiva.

Por fim, foi perguntado se o proprietário conhece o método o fluxo de caixa e se tem a pretensão de adotar. $\mathrm{O}$ administrador afirmou ter noção do que se trata um fluxo de caixa e relatou sua pretensão em se aprofundar nesse conhecimento, para que a empresa possa ter um retorno quanto ao desempenho dos custos.

Nada mais a questionar na entrevista, buscou-se verificar a estrutura financeira que a empresa possui. Como resposta, foi mostrada a tabela no Excel citada na entrevista que estava desatualizada, tanto em relação aos recebimentos dos clientes quanto a quantidade de alunos pagantes (procurou-se colocar uma tarja preta nos nomes a fim 
de proteger suas publicidades). As despesas estavam listadas, porém sem acompanhamento, como pode ser observado nas figuras 1, 2, 3 e 4.

Figura 1 - Planilha de recebíveis - Exercício de 2019

\begin{tabular}{|c|c|c|c|c|c|c|c|c|c|c|c|c|c|c|c|}
\hline \multirow{2}{*}{\begin{tabular}{c|c} 
& ROTA MATUTINO \\
NN & ALUNOS \\
\end{tabular}} & & & & & & & & & & & & & & & \\
\hline & ESCOLA & $P G$ & & LOR & JAN & FEV & MAR & $A B R$ & MAI & JUN & JUL & & JOUT & Nov & DEZ \\
\hline & & 05.17 & RS & 150,00 & & RS 150,00 & RS 150,00 & RS 150,00 & & & & & & & \\
\hline 2 & & \begin{tabular}{|l|}
05.19 \\
\end{tabular} & RS & 100,00 & & & RS 100,00 & RS 100,00 & & & & & & & 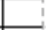 \\
\hline 3 & & \begin{tabular}{|l|l|}
07.18 \\
\end{tabular} & RS & 200,00 & & $\operatorname{RS} 200,00$ & RS 200,00 & $\operatorname{RS} 200,00$ & & & & & & & 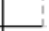 \\
\hline & & \begin{tabular}{|l|}
10.16 \\
\end{tabular} & RS & 220,00 & & RS 220,00 & RS 220,00 & $R S 220,00$ & & & & & & & \\
\hline 5 & & \begin{tabular}{|l|}
10.16 \\
\end{tabular} & RS & 220,00 & & $\operatorname{RS} 220,00$ & $\operatorname{RS} 220,00$ & RS 220,00 & $\operatorname{RS} 220,00$ & & & & & & - \\
\hline 6 & & 10.17 & RS & 160,00 & & RS 160,00 & RS 160,00 & & & & & & & & \\
\hline 7 & & 10.18 & RS & 220,00 & & RS 220,00 & RS 220,00 & RS 150,00 & & & & & & & - \\
\hline 8 & & \begin{tabular}{|l|}
10.18 \\
\end{tabular} & RS & 200,00 & & RS 200,00 & RS 200,00 & & & & & & & & Z \\
\hline & & \begin{tabular}{|l|}
10.18 \\
\end{tabular} & RS & 230,00 & & RS 230,00 & & & & & & & & & \\
\hline 10 & & 10.19 & RS & 200,00 & & RS 200,00 & RS 200,00 & $\operatorname{RS} 200,00$ & & & & & & & 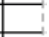 \\
\hline 11 & & 10.19 & RS & & & & & & & & & & & & \\
\hline 12 & & 10.19 & RS & 100,00 & & & & & & & & & & & 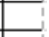 \\
\hline 13 & & 10.19 & RS & 100,00 & & & & & & & & & & & 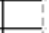 \\
\hline & & \begin{tabular}{|l|}
10.19 \\
\end{tabular} & RS & 100,00 & & $\operatorname{RS} 250,00$ & RS 250,00 & & & & & & & & 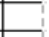 \\
\hline 15 & & 10.19 & RS & 350,00 & & RS 250,00 & RS 350,00 & & & & & & & & 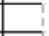 \\
\hline 16 & & 10.19 & RS & 350,00 & & $\operatorname{RS} 350,00$ & RS 350,00 & & & & & & & & \\
\hline 17 & & \begin{tabular}{|l|}
10.19 \\
\end{tabular} & RS & 200,00 & & RS 300,00 & RS 300,00 & RS 300,00 & $\operatorname{RS} 300,00$ & RS 300,00 & & & & & 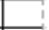 \\
\hline 18 & & \begin{tabular}{|l|}
10.19 \\
\end{tabular} & RS & 300,00 & & RS 300,00 & RS 300,00 & $R S 300,00$ & RS 300,00 & $R \$ 300,00$ & $\operatorname{RS} 300,00$ & & & & \\
\hline & & \begin{tabular}{|l|l|}
24.16 \\
\end{tabular} & RS & 135,00 & & RS 135,00 & RS 135,00 & & & & & & & & \\
\hline 20 & & \begin{tabular}{|l|}
24.19 \\
\end{tabular} & RS & 135,00 & & RS 135,00 & RS 135,00 & & & & & & & & 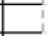 \\
\hline 21 & & 30.19 & RS & 100,00 & & RS 100,00 & RS 100,00 & RS 100,00 & & & & & & & \\
\hline 22 & & \begin{tabular}{|l|}
30.19 \\
\end{tabular} & RS & 250,00 & & RS 250,00 & RS 250,00 & $\operatorname{RS} 250,00$ & & & & & & & \\
\hline 23 & & \begin{tabular}{|l|}
30.19 \\
\end{tabular} & RS & 200,00 & & RS 200,00 & RS 200,00 & & & & & & & & - \\
\hline & & & & & & & & & & & & & & & -1 \\
\hline
\end{tabular}

Fonte: arquivos da Silvan Transportes

Figura 2 - Continuação da Planilha de Recebíveis - Exercício 2019

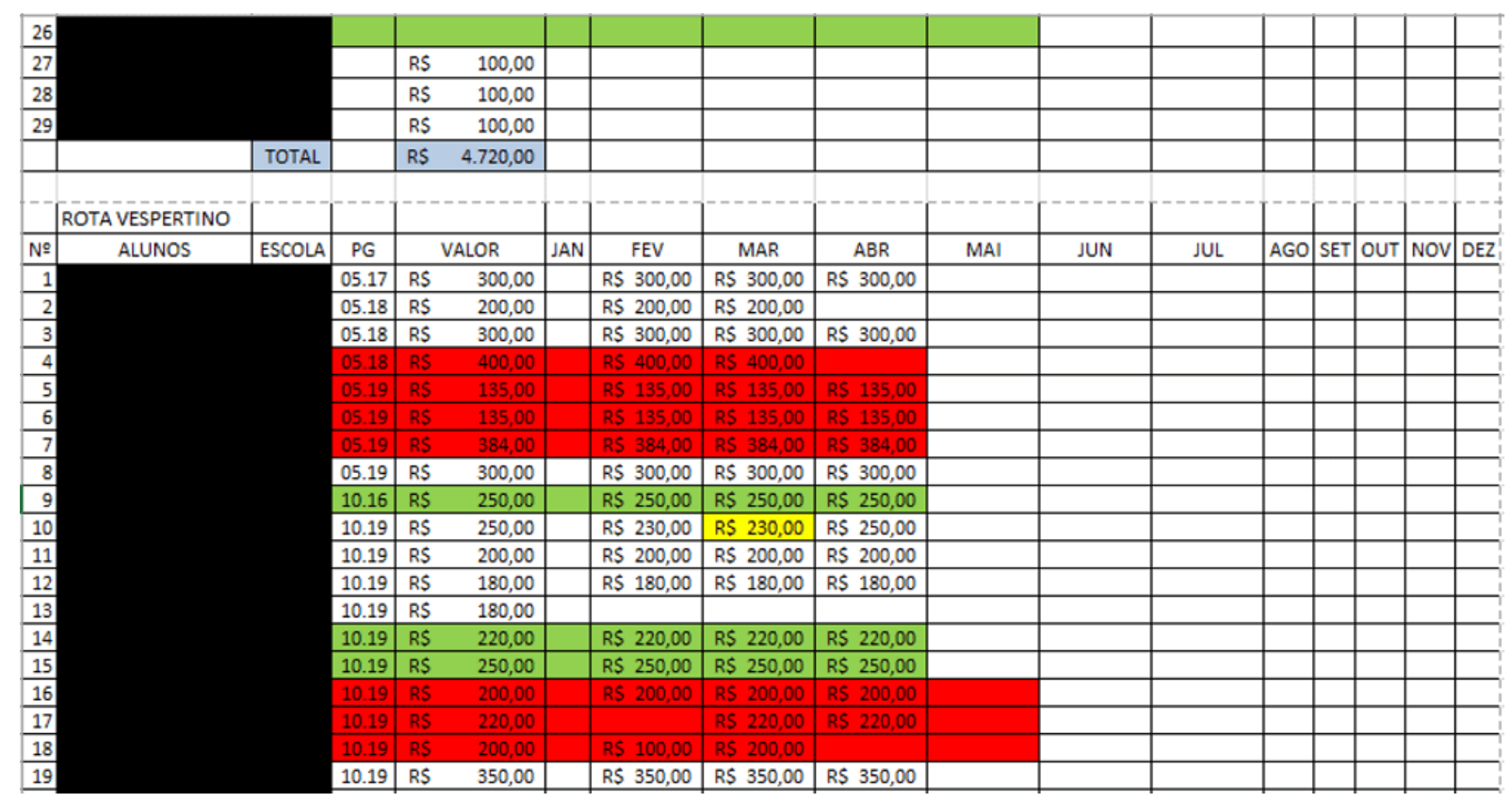

Fonte: arquivos da Silvan Transportes

$\mathrm{RC}: 43715$

Disponível em: https://www.nucleodoconhecimento.com.br/administracao/analise-financeira 
Figura 3 - Continuação da Planilha de Recebíveis - Exercício de 2019

\begin{tabular}{|c|c|c|c|c|c|c|c|c|c|c|c|c|c|c|}
\hline 20 & & 10.19 & RS & 350,00 & RS 350,00 & RS 350,00 & RS 350,00 & & & & & & & \\
\hline 21 & & 10.19 & RS & 300,00 & RS 300,00 & RS 300,00 & RS 300,00 & & & & & & & \\
\hline 22 & & 10.19 & RS & 250,00 & RS 250,00 & RS 250,00 & RS 250,00 & & & & & & & \\
\hline 23 & & 15.19 & RS & 400,00 & RS 400,00 & RS 400,00 & & & & & & & & \\
\hline 24 & & 30.19 & RS & 200,00 & RS 200,00 & RS 200,00 & RS 200,00 & & & & & & & \\
\hline 25 & & 30.19 & RS & 250,00 & RS 250,00 & RS 250,00 & & & & & & & & \\
\hline 26 & & 30.19 & RS & 200,00 & RS 200,00 & RS 200,00 & & & & & & & & \\
\hline 27 & & 30.19 & RS & 350,00 & RS 150,00 & RS 350,00 & RS 350,00 & & & & & & & \\
\hline 28 & & 30.19 & RS & 350,00 & & RS 350,00 & RS 350,00 & & & & & & & \\
\hline 29 & & 30.19 & RS & 250,00 & RS 250,00 & RS 250,00 & RS 250,00 & & & & & & & \\
\hline 30 & & & & & & RS 200,00 & RS 200,00 & & & & & & & \\
\hline 31 & & & & & & & & & & & & & & \\
\hline 32 & & & & & & & & & & & & & & \\
\hline 33 & & & RS & 200,00 & & & & & & & & & & \\
\hline & TOTAL & & $\mathrm{RS}$ & $7.754,00$ & & & & & & & & & & \\
\hline & & & & & & & & & & & & & & \\
\hline & TOTAL & & $R S$ & $12.474,00$ & & & & & & & & & & \\
\hline
\end{tabular}

Fonte: arquivos da Silvan Transportes

Figura 4 - Planilha de despesas fixas

\begin{tabular}{|c|c|c|}
\hline DESPESAS FIXAS & & \\
\hline ONIBUS & $\mathrm{R} \$$ & $3.000,00$ \\
\hline COMBUSTIVEL & $\mathrm{R} \$$ & $3.520,00$ \\
\hline MOTORISTA & $\mathrm{R} \$$ & $1.200,00$ \\
\hline MONITORA & $\mathrm{R} \$$ & $1.400,00$ \\
\hline TROCA DE OLEO & $\mathrm{R} \$$ & 300,00 \\
\hline TERRENO/MARLY & $\mathrm{R} \$$ & $2.000,00$ \\
\hline TOTAL & RS & $.420,00$ \\
\hline
\end{tabular}

Fonte: arquivos da Silvan Transportes

Com os dados obtidos, observou-se que o saldo mensal da empresa era positivo em $R \$ 1.054,00$, sendo $R \$ 12.474,00$ de recebíveis e despesas fixas no valor de $R \$$ $11.420,00$.

A importância de uma empresa de pequeno porte possuir controle financeiro efetivo foi passada ao proprietário por meio da apresentação dos trabalhos de Sousa (2014) e Antonick (2016), sendo também apresentada a estrutura do fluxo de caixa segundo os autores citados no referencial teórico deste artigo. 
O administrador se agradou do método apresentado e permitiu a aplicação dele na empresa, sendo, então, os dados referentes aos recebimentos, quantidade de alunos e despesas atualizados.

Assim, observou-se que as despesas fixas da empresa são: prestação de um dos veículos (nota promissória) no valor de $R \$ 3.000,00$, combustível no valor de $R \$$ $3.520,00$, salários no valor de $R \$ 1.900,00$, terreno (nota promissória) no valor de $R \$$ $1.000,00$, água no valor de $R \$ 39,00$, telefone/internet no valor de $R \$ 139,00$ e manutenção no valor de $R \$ 1.000,00$.

Em posse dos recebíveis e das despesas, as contas foram dispostas em uma tabela referente ao fluxo de caixa diário do mês de outubro/2019 (quadro 1), com percepção mais enxuta na figura 5 , verificando-se que a empresa recebe montante de $R \$$ $10.340,00$ e as despesas são superiores, $R \$ 10.598,00$, situação diferente da apresentada inicialmente.

Quadro 1 - Fluxo de caixa diário da Silvan Transportes - Outubro/2019

\begin{tabular}{|c|c|c|c|c|c|c|c|}
\hline & $\begin{array}{l}\text { Ingresso } \\
\mathrm{s}\end{array}$ & $\begin{array}{l}\text { Promiss } \\
\text { órias a } \\
\text { pagar }\end{array}$ & $\begin{array}{l}\text { Combus } \\
\text { tível }\end{array}$ & Salários & $\begin{array}{l}\text { Comunic } \\
\text { ação }\end{array}$ & Água & $\begin{array}{l}\text { Manuten } \\
\text { ção }\end{array}$ \\
\hline $\begin{array}{l}01 / \\
\text { out }\end{array}$ & - & $\mathrm{R} \$$ & $\mathrm{R} \$$ & $\mathrm{R} \$$ & $\mathrm{R} \$$ & $\mathrm{R} \$$ & $\mathrm{R} \$$ \\
\hline $\begin{array}{l}02 / \\
\text { out }\end{array}$ & - & $\mathrm{R} \$$ & $\mathrm{R} \$$ & $\mathrm{R} \$$ & $\mathrm{R} \$$ & $\mathrm{R} \$$ & $\mathrm{R} \$$ \\
\hline $\begin{array}{l}03 / \\
\text { out }\end{array}$ & - & $\mathrm{R} \$$ & $\mathrm{R} \$$ & $\mathrm{R} \$$ & $\mathrm{R} \$$ & $\mathrm{R} \$$ & $\mathrm{R} \$$ \\
\hline $\begin{array}{l}04 / \\
\text { out }\end{array}$ & - & $\mathrm{R} \$$ & $\mathrm{R} \$$ & $\mathrm{R} \$$ & $\mathrm{R} \$$ & $\mathrm{R} \$$ & $\mathrm{R} \$$ \\
\hline $\begin{array}{l}05 / \\
\text { out }\end{array}$ & $\begin{array}{ll}R \$ 1.3 \\
50,00\end{array}$ & $\begin{array}{cc}\mathrm{R} \$ & 1.0 \\
00,00 & \end{array}$ & $\begin{array}{cc}R \$ & 3 \\
50,00 & \end{array}$ & $\mathrm{R} \$$ & $\mathrm{R} \$$ & $\mathrm{R} \$$ & $\mathrm{R} \$$ \\
\hline
\end{tabular}




\begin{tabular}{|c|c|c|c|c|c|c|c|}
\hline $\begin{array}{l}06 / \\
\text { out }\end{array}$ & - & $\mathrm{R} \$$ & $\mathrm{R} \$$ & $\mathrm{R} \$$ & $\mathrm{R} \$$ & $\mathrm{R} \$$ & $\mathrm{R} \$$ \\
\hline $\begin{array}{l}07 / \\
\text { out }\end{array}$ & $\begin{array}{ll}\mathrm{R} \$ & 2 \\
00,00 & \end{array}$ & $\mathrm{R} \$$ & $\mathrm{R} \$$ & $\mathrm{R} \$$ & $\mathrm{R} \$$ & $\begin{array}{l}\mathrm{R} \$ \\
-\end{array}$ & $\mathrm{R} \$$ \\
\hline $\begin{array}{l}08 / \\
\text { out }\end{array}$ & - & $\mathrm{R} \$$ & $\mathrm{R} \$$ & $\mathrm{R} \$$ & $\mathrm{R} \$$ & $\begin{array}{l}\mathrm{R} \$ \\
-\end{array}$ & $\mathrm{R} \$$ \\
\hline $\begin{array}{l}09 / \\
\text { out }\end{array}$ & - & $\begin{array}{r}\mathrm{R} \$ \\
-\end{array}$ & $\mathrm{R} \$$ & $\begin{array}{r}\mathrm{R} \$ \\
-\end{array}$ & $\mathrm{R} \$$ & $\mathrm{R} \$$ & $\mathrm{R} \$$ \\
\hline $\begin{array}{l}10 / \\
\text { out }\end{array}$ & $\begin{array}{cc}\mathrm{R} \$ & 6.1 \\
70,00 & \end{array}$ & $\begin{array}{ll}R \$ & 2.0 \\
00,00 & \end{array}$ & $\begin{array}{l}R \$ 2.2 \\
31,00\end{array}$ & $\begin{array}{l}\mathrm{R} \$ 1.9 \\
00,00\end{array}$ & $\mathrm{R} \$$ & $\begin{array}{l}\mathrm{R} \$ \\
9,00\end{array}$ & $\mathrm{R} \$$ \\
\hline $\begin{array}{l}11 / \\
\text { out }\end{array}$ & - & $\mathrm{R} \$$ & $\mathrm{R} \$$ & $\mathrm{R} \$$ & $\mathrm{R} \$$ & $\mathrm{R} \$$ & $\mathrm{R} \$$ \\
\hline $\begin{array}{l}12 / \\
\text { out }\end{array}$ & - & $\begin{array}{r}R \$ \\
-\end{array}$ & $\mathrm{R} \$$ & $\begin{array}{r}\mathrm{R} \$ \\
-\end{array}$ & $\mathrm{R} \$$ & $\mathrm{R} \$$ & $\mathrm{R} \$$ \\
\hline $\begin{array}{l}13 / \\
\text { out }\end{array}$ & - & $\begin{array}{r}\mathrm{R} \$ \\
-\end{array}$ & $R \$$ & $\mathrm{R} \$$ & $\mathrm{R} \$$ & $\mathrm{R} \$$ & $\mathrm{R} \$$ \\
\hline $\begin{array}{l}14 / \\
\text { out }\end{array}$ & - & $\mathrm{R} \$$ & $\mathrm{R} \$$ & $\begin{array}{r}\mathrm{R} \$ \\
-\end{array}$ & $\mathrm{R} \$$ & $\mathrm{R} \$$ & $\mathrm{R} \$$ \\
\hline $\begin{array}{l}15 / \\
\text { out }\end{array}$ & $\begin{array}{c}\mathrm{R} \$ \\
00,00\end{array}$ & $\mathrm{R} \$$ & $\mathrm{R} \$$ & $\mathrm{R} \$$ & $\begin{array}{cc}\mathrm{R} \$ & 1 \\
39,00 & \end{array}$ & $\mathrm{R} \$$ & $\mathrm{R} \$$ \\
\hline $\begin{array}{l}16 / \\
\text { out }\end{array}$ & - & $\begin{array}{r}\mathrm{R} \$ \\
-\end{array}$ & $\mathrm{R} \$$ & $\begin{array}{r}\mathrm{R} \$ \\
-\end{array}$ & $R \$$ & $\mathrm{R} \$$ & $\mathrm{R} \$$ \\
\hline $\begin{array}{l}17 / \\
\text { out }\end{array}$ & - & $\begin{array}{r}\mathrm{R} \$ \\
-\end{array}$ & $R \$$ & $\begin{array}{r}R \$ \\
-\end{array}$ & $\mathrm{R} \$$ & $\mathrm{R} \$$ & $\begin{array}{r}\mathrm{R} \\
-\end{array}$ \\
\hline $\begin{array}{l}18 / \\
\text { out }\end{array}$ & - & $\begin{array}{r}\mathrm{R} \$ \\
-\end{array}$ & $\mathrm{R} \$$ & $\begin{array}{r}R \$ \\
-\end{array}$ & $\mathrm{R} \$$ & $\mathrm{R} \$$ & $\mathrm{R} \$$ \\
\hline $\begin{array}{l}19 / \\
\text { out }\end{array}$ & - & $\mathrm{R} \$$ & $\mathrm{R} \$$ & $\mathrm{R} \$$ & $\mathrm{R} \$$ & $\mathrm{R} \$$ & $\mathrm{R} \$$ \\
\hline $\begin{array}{l}20 / \\
\text { out }\end{array}$ & - & $\mathrm{R} \$$ & $\mathrm{R} \$$ & $\mathrm{R} \$$ & $\mathrm{R} \$$ & $\mathrm{R} \$$ & $\mathrm{R} \$$ \\
\hline
\end{tabular}




\begin{tabular}{|c|c|c|c|c|c|c|c|}
\hline $\begin{array}{l}21 / \\
\text { out }\end{array}$ & - & $\begin{array}{c}\mathrm{R} \$ \\
-\end{array}$ & $\mathrm{R} \$$ & $\begin{array}{c}\mathrm{R} \$ \\
-\end{array}$ & $\mathrm{R} \$$ & $\begin{array}{l}\mathrm{R} \$ \\
-\end{array}$ & $\begin{array}{r}\mathrm{R} \$ \\
-\end{array}$ \\
\hline $\begin{array}{l}\text { 22/ } \\
\text { out }\end{array}$ & - & $\mathrm{R} \$$ & $\mathrm{R} \$$ & $\begin{array}{r}\mathrm{R} \$ \\
-\end{array}$ & $\mathrm{R} \$$ & $\mathrm{R} \$$ & $\begin{array}{r}\mathrm{R} \$ \\
-\end{array}$ \\
\hline $\begin{array}{l}23 / \\
\text { out }\end{array}$ & - & $\mathrm{R} \$$ & $\mathrm{R} \$$ & $\mathrm{R} \$$ & $\mathrm{R} \$$ & $\mathrm{R} \$$ & $\mathrm{R} \$$ \\
\hline $\begin{array}{l}24 / \\
\text { out }\end{array}$ & $\begin{array}{ll}\mathrm{R} \$ & 2 \\
70,00 & \end{array}$ & $\mathrm{R} \$$ & $\mathrm{R} \$$ & $\mathrm{R} \$$ & $\mathrm{R} \$$ & $\mathrm{R} \$$ & $\mathrm{R} \$$ \\
\hline $\begin{array}{l}25 / \\
\text { out }\end{array}$ & - & $\mathrm{R} \$$ & $\mathrm{R} \$$ & $\mathrm{R} \$$ & $\mathrm{R} \$$ & $\mathrm{R} \$$ & $\mathrm{R} \$$ \\
\hline $\begin{array}{l}26 / \\
\text { out }\end{array}$ & - & $\mathrm{R} \$$ & $\mathrm{R} \$$ & $\mathrm{R} \$$ & $\mathrm{R} \$$ & $\mathrm{R} \$$ & $\begin{array}{r}\mathrm{R} \$ \\
-\end{array}$ \\
\hline $\begin{array}{l}27 / \\
\text { out }\end{array}$ & - & $\mathrm{R} \$$ & $\mathrm{R} \$$ & $\begin{array}{r}\mathrm{R} \$ \\
-\end{array}$ & $\mathrm{R} \$$ & $\mathrm{R} \$$ & $\begin{array}{r}\mathrm{R} \$ \\
-\end{array}$ \\
\hline $\begin{array}{l}28 / \\
\text { out }\end{array}$ & - & $\begin{array}{r}\mathrm{R} \$ \\
-\end{array}$ & $\mathrm{R} \$$ & $\begin{array}{r}\mathrm{R} \$ \\
-\end{array}$ & $\mathrm{R} \$$ & $\mathrm{R} \$$ & $\begin{array}{r}\mathrm{R} \$ \\
-\end{array}$ \\
\hline $\begin{array}{l}29 / \\
\text { out }\end{array}$ & - & $\begin{array}{r}\mathrm{R} \$ \\
-\end{array}$ & $\mathrm{R} \$$ & $\mathrm{R} \$$ & $\mathrm{R} \$$ & $\mathrm{R} \$$ & $\mathrm{R} \$$ \\
\hline $\begin{array}{l}30 / \\
\text { out }\end{array}$ & $\begin{array}{l}\mathrm{R} \$ \quad 2.1 \\
50,00\end{array}$ & $\begin{array}{cc}\mathrm{R} \$ & 1.0 \\
00,00 & \end{array}$ & $\begin{array}{cc}\mathrm{R} \$ & 9 \\
39,00 & \end{array}$ & $\begin{array}{r}\mathrm{R} \$ \\
-\end{array}$ & $\mathrm{R} \$$ & $\mathrm{R} \$$ & $\begin{array}{l}\mathrm{R} \$ 1.0 \\
00,00\end{array}$ \\
\hline $\begin{array}{l}31 / \\
\text { out }\end{array}$ & - & $\mathrm{R} \$$ & $\mathrm{R} \$$ & $\begin{array}{r}\mathrm{R} \$ \\
-\end{array}$ & $\mathrm{R} \$$ & $\mathrm{R} \$$ & $\begin{array}{r}\mathrm{R} \$ \\
-\end{array}$ \\
\hline $\begin{array}{l}\text { Tot } \\
\text { al }\end{array}$ & $\begin{array}{l}R \$ 10.3 \\
40,00\end{array}$ & $\begin{array}{ll}R \$ & 4.0 \\
00,00 & \end{array}$ & $\begin{array}{l}R \$ 3.5 \\
20,00\end{array}$ & $\begin{array}{l}\mathrm{R} \$ 1.9 \\
00,00\end{array}$ & $\begin{array}{cc}\mathrm{R} \$ & 1 \\
39,00 & \end{array}$ & $\begin{array}{l}\mathrm{R} \$ \quad 3 \\
9,00\end{array}$ & $\begin{array}{l}R \$ 1.0 \\
00,00\end{array}$ \\
\hline
\end{tabular}

Fonte: autoria própria 
Figura 5 - Fluxo de Caixa da Silvan Transportes - Mês de outubro/2019

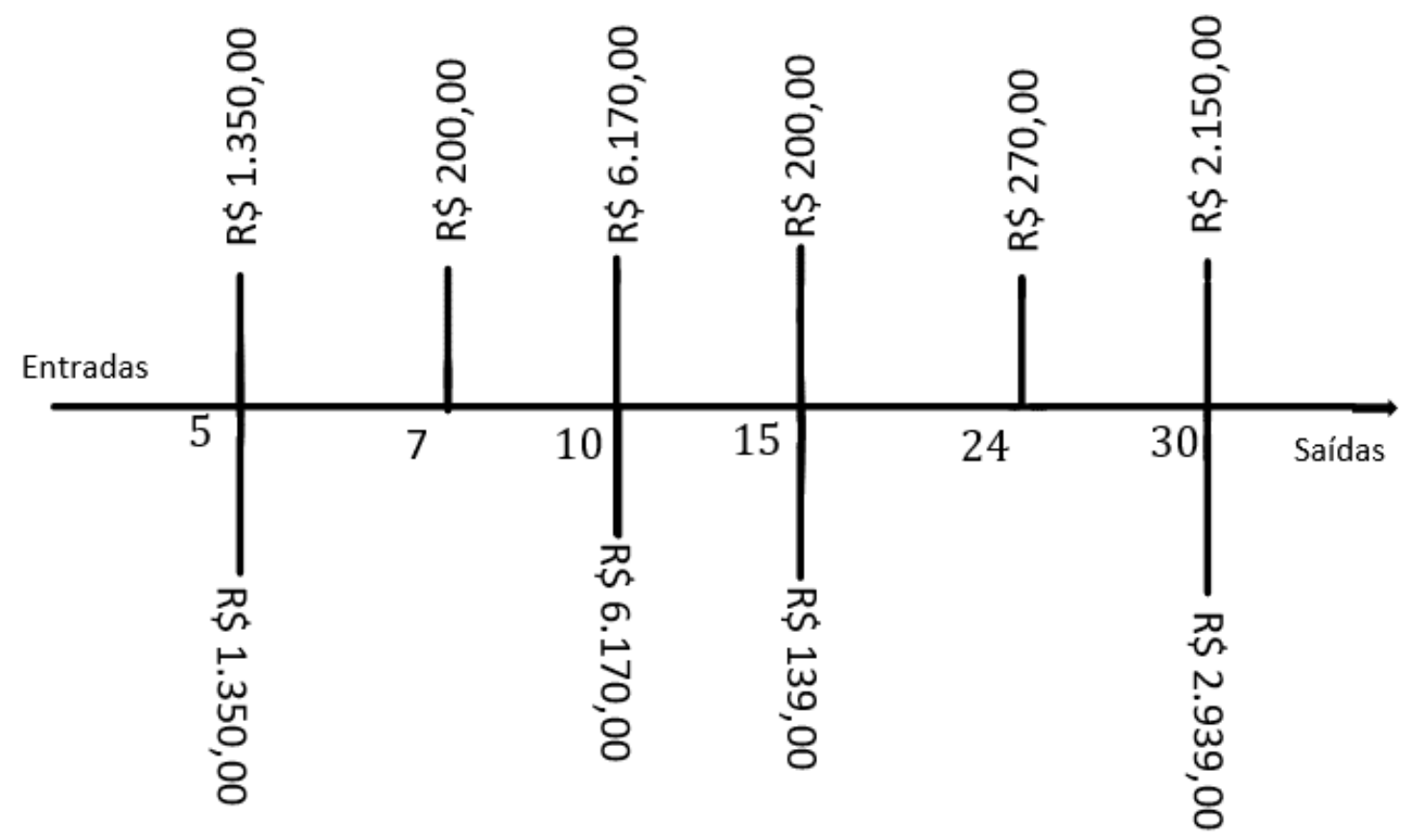

Fonte: autoria própria

Após ser verificado que o saldo da empresa finaliza negativo em $R \$ 258,00$, o administrador foi questionado sobre a capacidade de sobrevivência da empresa durante o período, já que as despesas são fixas e não se tem dados referentes ao tempo que a empresa está com situação negativa, afinal os dados da empresa estavam desatualizados. Como resposta, foi explicado que a conta manutenção é tida como despesa fixa de caráter preventivo, em que certo mês são trocados os pneus, no outro mês é realizada troca de óleo e assim por diante. Ocorre que, como o saldo que a empresa recebe é inferior aos gastos que possui, o valor de $\mathrm{R} \$ 1.000,00$ acaba sofrendo perdas para que todas as dívidas sejam sanadas. Ou seja, nem sempre o valor total é destinado à manutenção, reduzindo-se para alcançar a liquidez.

Outra conta que despertou curiosidade foi o terreno. Segundo relatos, o valor de $R \$$ $1.000,00$ refere-se a parte do salário do proprietário da empresa que utiliza o valor para pagar um térreo de uso pessoal, verificando, dessa forma, que o controle financeiro da empresa não se refere apenas aos recebimentos e pagamentos da mesma, findando na confusão dos bens pessoais com os da organização. No entanto, 
para fins de verificação da situação financeira, tal conta foi tomada como nota promissória, por ser um comprometimento que a empresa está tomando.

Com os dados do fluxo de caixa da Silvan Transportes, referente ao mês de outubro/2019, buscou-se identificar a situação financeira da organização por meio de índices, sendo necessário, primeiramente, as contas serem organizadas em ativos, passivos e patrimônio líquido, formando-se o Balanço Patrimonial do mês de outubro/2019 (quadro 2).

Quadro 2 - Balanço Patrimonial da Silvan Transportes ME - Exercício Outubro/2019

\begin{tabular}{|c|c|c|c|c|}
\hline $\begin{array}{c}\text { ATIVO } \\
\text { ATIVO CIRCULANTE }\end{array}$ & & $\begin{array}{c}\text { PASSIVO } \\
\text { PASSIVO CIRCULANTE }\end{array}$ & & \\
\hline Clientes & $\mathrm{R} \$ 10.340,00$ & Promissória a pagar & $\mathrm{RS}$ & $4.000,00$ \\
\hline & & Combustível & $\mathrm{R} \$$ & $3.520,00$ \\
\hline & & Salários a pagar & $\mathrm{RS}$ & $1.900,00$ \\
\hline & & Comunicação & RS & 139,00 \\
\hline & & Água e esgoto & RS & 39,00 \\
\hline & & Manutenção & $\mathrm{RS}$ & $1.000,00$ \\
\hline ATIVO NÃO CIRCULANTE & & PASSIVO NÃO CIRCULANTE & & \\
\hline Veículos & $\mathrm{R} \$ 182.000,00$ & & & \\
\hline Depreciação acumulada & $(\mathrm{R} \$ 182.000,00)$ & & & \\
\hline TOTAL DO ATIVO & RS $10.340,00$ & $\begin{array}{l}\text { PATRIMÔNIO LÍQUIDO } \\
\text { Lucro/Prejuízo acumulado } \\
\text { TOTAL DO PASSIVO }\end{array}$ & $\begin{array}{l}\text { (R } \\
\text { RS }\end{array}$ & $\begin{array}{c}258,00) \\
\mathbf{1 0 . 3 4 0 , 0 0}\end{array}$ \\
\hline
\end{tabular}

Fonte: autoria própria

Desta feita, conforme observa-se no Balanço Patrimonial, as fontes de recurso à disposição da empresa são de $R \$ 10.340,00$, sendo que $R \$ 258,00$ indica o prejuízo do capital próprio e $\mathrm{R} \$ 10.598,00$ corresponde ao capital de terceiros. Também se verifica que as fontes de recurso à disposição da empresa foram aplicadas em sua totalidade no Ativo Circulante, com valor de $\mathrm{R} \$ 10.340,00$.

A fim de obter um bom diagnóstico quanto à situação financeira da organização, cabe ao gestor a composição de um quadro com a situação patrimonial da entidade. A situação financeira é evidenciada pelos índices de capitais e de liquidez. 
A estrutura de capitais mostra as grandes linhas de decisões financeiras em termos de obtenção e aplicação dos recursos e a estrutura de liquidez mostra a capacidade financeira da empresa para pagamento de suas dívidas.

Os índices de Estrutura de Capitais servem para evidenciar o grau de endividamento da empresa em decorrência das origens dos capitais investidos no patrimônio. Eles demonstram a proporção existente entre os capitais próprios e os capitais de terceiros, sendo calculados através dos valores extraídos do Balanço Patrimonial.

Os índices de capitais próprios avaliam o grau de dependência da empresa em recursos próprios (Capital Social, Reservas, Lucros etc.) e sua aplicação no ativo. Os principais índices são índice de Participação de Capitais Próprios sobre o Ativo, que tem como objetivo comparar os recursos de Capital Próprio com aplicações no Ativo, e Índice de Participação de Capitais Próprios sobre o Capital de Giro, que visa comparar os recursos de Capital Próprio com as aplicações no Ativo Circulante.

O Índice de Participação de Capitais Próprios sobre o Ativo é obtido através da fórmula: $\left(\frac{P L}{A T}\right) \times 100$. Na Silvan Transportes, as aplicações no Ativo, financiadas por Capital Próprio representam - 2,50\%, ou seja, a cada $R \$ 1,00$ investido no ativo, $\mathrm{R} \$ 0,02$ é obtido do Capital Próprio, indicando uma situação ruim.

Já o Índice de Participação de Capitais Próprios sobre o Capital de Giro é obtido através da fórmula: $\left(\frac{P L}{A C}\right) \times 100$. No objeto de estudo, identificou-se que as aplicações no Ativo Circulante (Capital de Giro) são financiadas por - 2,50\% de Capital Próprio.

As taxas acima foram idênticas em razão da empresa não possuir Ativo Não Circulante, já que os bens estão depreciados e o balanço é referente apenas o mês de outubro do corrente ano. 
A liquidez da empresa, nesse caso foi avaliada através do Índice de Liquidez Corrente, que "mostra quantos reais a empresa tem para pagar as dívidas de curto prazo" (ANTONIK, 2016, p. 217). É obtida através da equação: $\left(\frac{A C}{P C}\right) \times 100$. A Silvan Transportes apresentou liquidez corrente de $98 \%$, valor abaixo do recomendado (100\%), indicando que não tem capacidade de saldar suas dívidas no curto prazo. A cada $R \$ 1,00$ de dívida a empresa tem recurso no valor de $R \$ 0,98$.

A Situação Líquida Patrimonial é obtida através da fórmula: SLP = AT - Passivo Exigível, , em que Passivo Exigível é o Capital de Terceiros, ou seja, passivo circulante mais passivo não circulante. No presente caso, a situação da empresa é deficitária em $R \$ 258,00$, não possuindo riqueza própria, com risco elevado de insolvência técnica, indicando que o patrimônio bruto é insuficiente para financiar (pagar) as dívidas, situação de Passivo a descoberto.

"O Índice de Participação de Capital de Terceiros é conhecido a contabilidade como Dependência de Recurso de Terceiros (DRT), pois aponta o volume dos recursos de terceiros usados na atividade da empresa" (ANTONIK, 2016. p. 224). É obtido através da equação: $\left(\frac{\text { Passivo total-Patrimônio Liquido }}{\text { Ativo Total })}\right.$. O resultado na Silvan Transportes foi de 1,02 , indicando que $102 \%$ dos capitais que financiam a firma são de terceiros, sendo grande a chance de insolvência.

O índice de Composição do Endividamento tem como objetivo comparar os recursos das obrigações a curto prazo (Passivo Circulante) com os recursos de Capitais de Terceiros (obrigações de curto e longo prazo). Seu valor é descoberto através da equação: $\left(\frac{P C}{P E}\right) \times 100$. Na empresa objeto de estudo, $100 \%$ das dívidas estão no curto prazo. 
"O Índice de Solvência Geral mede a liquidez total da empresa por intermédio da comparação de todas as obrigações que são exigíveis da mesma (passivo circulante e exigível em longo prazo), com uso do total de ativos" (ANTONIK, 2016, p. 221). É obtido através da fórmula: $\left(\frac{A T}{P E}\right) \times 100$. Como o total do Ativo Circulante é idêntico ao valor do Ativo Total, o resultado do Índice de Solvência Geral é o mesmo da Liquidez Corrente, 0,98, indicando que o total de Ativos é menor que as obrigações, apresentando situação de passivo a descoberto, um caso de Patrimônio Líquido negativo.

Em modo geral, observou-se que os índices financeiros demonstraram situação ruim da empresa. As dívidas são superiores aos recebimentos. A empresa não possui capacidade de liquidez e a composição do endividamento é de $100 \%$ no curto prazo. No fluxo de caixa direto, verificou-se que o problema maior das despesas ocorre no dia 30 , em que as saídas são maiores do que as entradas em $R \$ 258,00$.

\section{CONCLUSÃO}

Empresas de pequeno porte possuem diversas vantagens, sendo uma delas a não escrituração contábil em livros próprios. Ocorre que tal facilidade pode desencadear certo abandono do controle financeiro. Assim, tendo esse pano de fundo, um dos objetivos do presente instrumento foi a identificação do controle financeiro de uma empresa de pequeno porte, do ramo de transporte escolar, a Silvan Transportes ME.

A abordagem foi através de pesquisa documental e entrevista, em que se compreendeu que o controle financeiro da empresa se resumia em uma planilha do Excel que estava desatualizada, tanto no quesito recebimento, quanto pagamentos, evidenciando que a empresa possuía saldo positivo ao final de cada mês.

Outro objetivo da pesquisa era a instrução quanto ao método do fluxo de caixa, visto que tal método evidencia as entradas e saídas do caixa e contribui para o planejamento e tomada de decisão. Tal objetivo foi alcançado após as contas estarem atualizadas, observando que o saldo da empresa, ao final do mês de análise 
(outubro/2019) é negativo em $\mathrm{R} \$ 258,00$, No entanto tal situação acaba por ser contornada, tendo em vista que o valor que seria destinado à manutenção dos veículos não é totalmente utilizado para tal fim, cobrindo as despesas existentes.

O fluxo de caixa e os índices levantados neste trabalho despertaram o administrador da empresa para a importância de possuir um controle financeiro efetivo que auxilia o planejamento e a tomada de decisão, afinal, no longo prazo, a situação da empresa tende a ser pior do que a apresentada, caso nenhuma medida seja adotada.

A empresa possui dois carros cadastrados, porém a receita por eles gerada não está sendo suficiente para financiar todas as dívidas. Assim, a sugestão é o novo planejamento das despesas, com possível venda de um dos carros e união das rotas para reduzir a ociosidade. Após a situação da empresa estar ajustada, com reserva no caixa, indica-se a compra de carro que atenda às necessidades da empresa. Ainda, recomenda-se que o método do fluxo de caixa seja constantemente alimentado, para que as decisões não sejam tomadas sem o devido embasamento.

\section{REFERÊNCIAS}

ANTONICK, Luis Roberto. Empreendedorismo: Gestão Financeira para micro e pequenas empresas. $1^{\underline{a}}$ ed. Rio de Janeiro: Alta Books, 2016.

CAMARGO, Camila. Planejamento financeiro. $2^{\underline{a}}$ ed. rev. e atual. Curitiba: Ibpex, 2007.

CHING, Hong Yuh; MARQUES, Fernando; PRADO, Lucilene. Contabilidade e finanças para não especialistas. $2^{\mathrm{a}}$ ed. São Paulo: Pearson Prentice Hall, 2007.

GITMAN, Lawrence J. Princípios de administração financeira. 12ª ed. São Paulo: Pearson Prentice Hall, 2010.

GROPPELLI, A.A; NIKBAKHY, Ehsan. Administração financeira. 3ª ed. São Paulo: Saraiva, 2010. 
Planalto.

Disponível

em:

$<$ http://

www.planalto.gov.br/ccivil_03/leis/2002/10406.htm> Acesso em 12/05/2019 às $20 \mathrm{~h} 51$.

RIBEIRO, Osni Moura. Contabilidade básica fácil. 29ª ed. São Paulo: Saraiva, 2013.

ROESCH, Sylvia Maria Azevedo. Projetos de estágio e de pesquisa em administração: guia para estágios, trabalhos de conclusão, dissertações e estudos de caso. $3^{\text {a }}$ ed. São Paulo: Atlas, 2007.

SOUSA, Antonio de. Gerência Financeira para micro e pequenas empresas. $2^{\mathrm{a}}$ ed. Rio de Janeiro: Elsevier, 2014.

VERGARA, Sylvia Constant. Projetos e Relatórios de Pesquisa em Administração. 14ª ed. São Paulo: Atlas, 2013.

\section{APÊNDICE}

Formulário estruturado para levantamento de dados

1. É conhecida a importância de possuir um controle financeiro?

2. Acha que já perdeu alguma oportunidade por conta do controle financeiro?

3. Acredita que gasta mais do que ganha?

4. O controle financeiro que possui é suficiente/vantajoso?

5. Como as decisões quanto ao crescimento, estabelecimento de metas são tomadas?

6. Tem listadas todas as suas despesas? Possui comprovantes de pagamentos e recebimentos?

7. Conhece o método do fluxo de caixa? Se sim, tem a pretensão de adotar?

Enviado: Janeiro, 2020.

Aprovado: Janeiro, 2020. 